\title{
Publisher Correction: Molecular subtypes of diffuse large B cell lymphoma are associated with distinct pathogenic mechanisms and outcomes
}

Bjoern Chapuy, Chip Stewart, Andrew J. Dunford, Jaegil Kim, Atanas Kamburov, Robert A. Redd, Mike S. Lawrence, Margaretha G. M. Roemer, Amy J. Li, Marita Ziepert, Annette M. Staiger (D), Jeremiah A. Wala (D, Matthew D. Ducar, Ignaty Leshchiner D, Ester Rheinbay, Amaro Taylor-Weiner, Caroline A. Coughlin, Julian M. Hess, Chandra S. Pedamallu, Dimitri Livitz (D), Daniel Rosebrock, Mara Rosenberg, Adam A. Tracy, Heike Horn, Paul van Hummelen, Andrew L. Feldman (D, Brian K. Link, Anne J. Novak, James R. Cerhan, Thomas M. Habermann, Reiner Siebert, Andreas Rosenwald, Aaron R. Thorner, Matthew L. Meyerson (D), Todd R. Golub (D), Rameen Beroukhim, Gerald G. Wulf, German Ott, Scott J. Rodig, Stefano Monti, Donna S. Neuberg (D), Markus Loeffler, Michael Pfreundschuh, Lorenz Trümper, Gad Getz (D) and Margaret A. Shipp

Correction to: Nature Medicine https://doi.org/10.1038/s41591-018-0016-8, published online 30 April 2018.

In the version of this article originally published, some text above the "Tri-nucleotide sequence motifs" label in Fig. 2a appeared incorrectly. The text was garbled and should have appeared as nucleotide codes.

Additionally, the labels on the bars in Fig. $2 c$ were not italicized in the original publication. These are gene symbols, and they should have been italicized.

The colored labels above the graphs in Fig. $4 \mathrm{~b}$ were also erroneously not italicized. These labels represent gene names and loci, and they should have been italicized.

The errors have been corrected in the PDF and HTML versions of this article.

\section{Original figure}

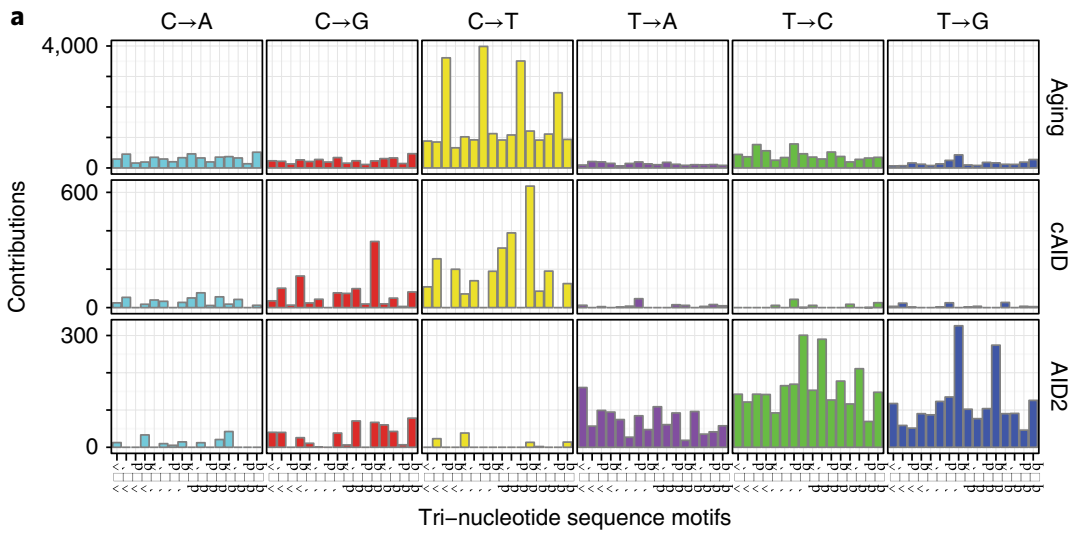

Corrected figure

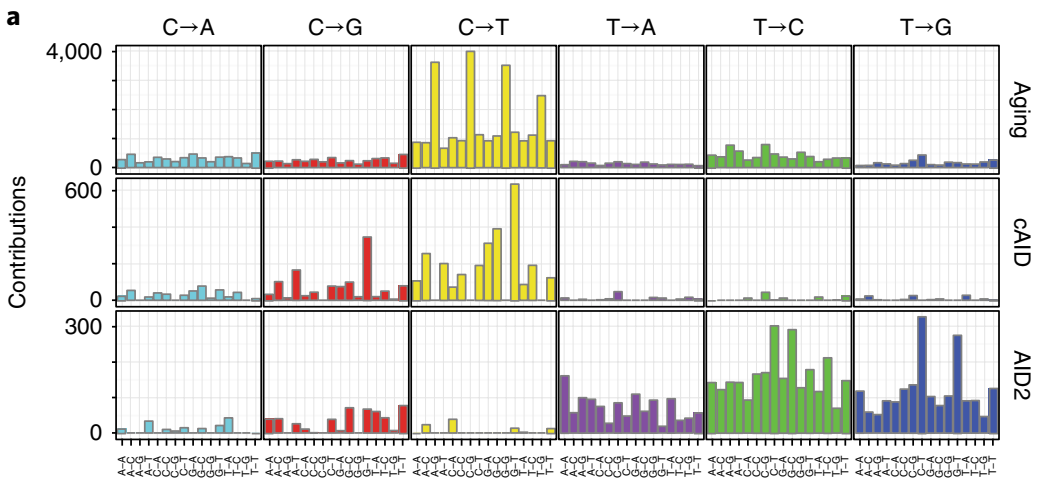

Fig. 2 | Original and corrected.

Tri-nucleotide sequence motifs 